\title{
Effect of Molecular Weight of Polyethylene Glycols on Inactivation of Mycoplasma pulmonis and Acholeplasma laidlawii A
}

\author{
RYUICHI HASHIMOTO AND MASAHIRO NAKAMURA \\ Department of Microbiology, Kurume University School of Medicine, \\ Kurume, 830 Japan
}

Received for publication December 22, 1982

\begin{abstract}
Summary: Toxicity of polyethylene glycol (PEG), one of the common fusogens to Mycoplasma pulmonis M53 and Acholeplasma laidlawii A was reported. For this, PEG with molecular weights of 200,600, 1000, 2000, 4000 and 6000 were mixed with suspensions of mycoplasmas and the survival of the mycoplasmas determined. The results obtained showed that the higher the molecular weight, the greater was the toxicity. The results presented here strongly suggest that the molecular weight of the PEG should be considered when an experiment on cell fusion in mycoplasmas is carried out.
\end{abstract}

Key words: mycoplasma - acholeplasma - polyethylene glycol - inactivation - cell fusion

\section{Introduction}

Mycoplasmas are known to be minimal organisms which are capable of independent growth and replication, and are believed to have minimal sets of genes for these activities. This speculation has been partially verified. The ribosomal RNA gene has been shown to be a single cistron in Mycoplasma capricolum. This simplicity seems to be a very useful property of mycoplasmas for genetic research. One more prominent property which is likely to be of use for genetic studies by the method of cell fusion is that mycoplasmas lack a cell wall, because, in the case of bacteria, protoplast formation is necessary before fusion can be induced by fusogens. In this study, as a basis for the fusion experiment with mycoplasmas, the toxicity of polyethylene glycols (PEG) to Mycoplasma pulmonis M53 and Acholeplasma laidlawii A was determined, in terms of their molecular weight and concentration. We chose these mycoplasmas as representative, because $M$. pulmonis has properties such as horse serum requirement for growth, haemadsorption and resistance to erythromycin as its biological markers. On the other hand, A. laidlawii dose not require horse serum for growth and is highly sensitive to erythromycin. These properties should be useful as selection markers when these mycoplasmas and acholeplasmas are employed for the fusion experiment. Our results, presented in this report, showed that the lower the molecular weight and the higher the concentration of polyethylene glycols, the greater was the toxicity to mycoplasmas and acholeplasmas.

\section{Materials and Methods}

Organisms and growth conditions: $M$. pulmonis M53 and A. laidlawii A were grown aerobically at $37^{\circ} \mathrm{C}$ in PPLO broth (Difco) supplemented with $20 \%$ horse se- 
rum and $10 \%$ yeast extract. After 2 days' cultivation, the organisms were harvested by centrifugation at $10,000 \mathrm{rpm}$ for 60 minutes in the cold and pellets were suspended in phosphate buffered saline.

Preparation of PEG solutions: The PEG solutions (molecular weights: 200, 600, $1000,2000,4000$ and 6000) were prepared by mixing solid or liquid PEGs with phosphate buffered saline and sterilized by autoclaving for 15 minutes at $121{ }^{\circ} \mathrm{C}$. The $\mathrm{pH}$ of the solutions was adjusted to 7.2. The final concentrations of the solutions were designed to be $10,20,30$ and $40 \%(\mathrm{w} / \mathrm{v})$, when $1.5 \mathrm{ml}$ of PEG solution was mixed with $0.5 \mathrm{ml}$ of the cell suspension.

Method for measuring survival of the cells: The cell suspensions were mixed with PEG solutions, after determination of the zero time viable cell counts, and the number of viable cells after 10 and 30 minutes' treatment with PEG was determined by the method of Smith. In this case, the effect of PEG itself was eliminated by 10 -fold dilution with phosphate buffered saline.

\section{Results}

Inactivation curves of $M$. pulmonis M 53 by PEGs of various molecular weights at a final concentration of $40 \%$ are shown in Fig. 1. In the case of the PEGs of less than $1000 \mathrm{~mol} \mathrm{wt}$, the inactivation of $M$. pulmonis is marked. Particularly in the case of PEG 200 , viable cells were significantly reduced to $4.45 \mathrm{log} \mathrm{CFU} / \mathrm{ml}$ by 10 minutes' treatment, from $6.21 \log \mathrm{CFU} / \mathrm{ml}$ for the starting material. In addition, no viable cells were recovered after 30 minutes' treatment. On the other hand, inactivation by the higher molecular weight PEGs was very slight. PEG 4000 and 6000, which have commonly been used for bacterial cell fusion, showed only slight toxicity to $M$. pulmonis M 53.

In the case of A. laidlawii A (Fig. 2), results similar to those with $M$. pulmonis

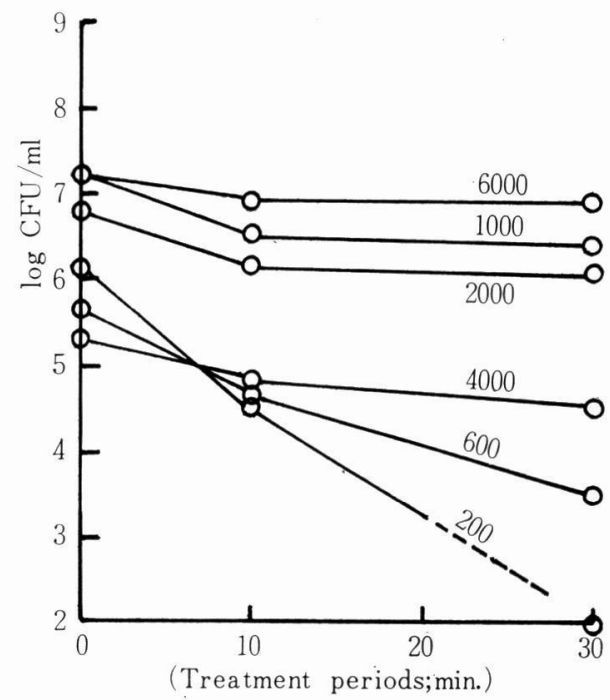

Fig. 1. Effect of molecular weight of PEG $(40 \%)$ on inactivation of $M$. pulmonis.

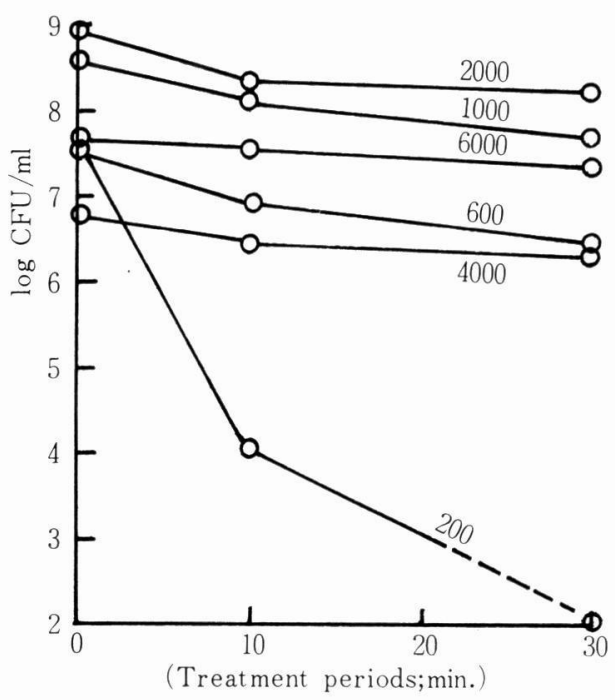

Fig. 2. Effect of molecular weight of PEG $(40 \%)$ on inactivation of $A$. laidlawii $\mathrm{A}$.

were obtained. No viable cells were observed after treatment with PEG 200 for 30 minutes, whereas PEG 6000 showed only a very slight decrease in the number of surviving A. laidlawii A cells. These results 


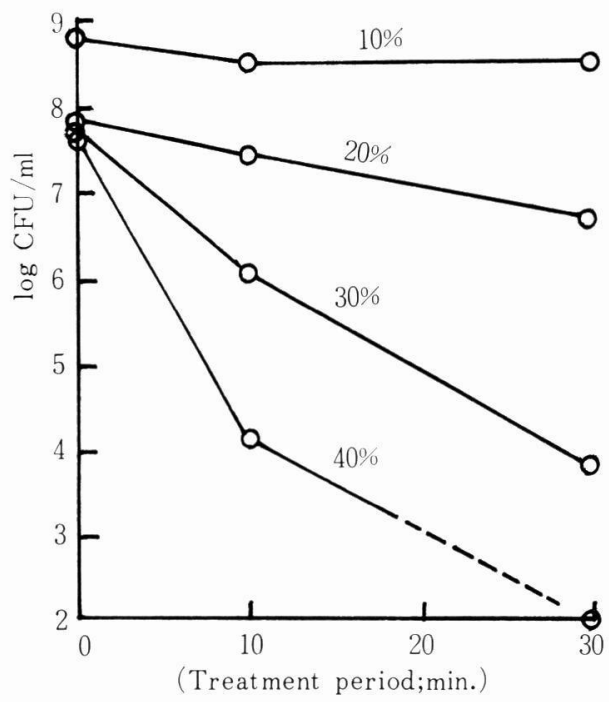

Fig. 3. Inactivation of $A$. laidlawii A by various concentrations of PEG 200.

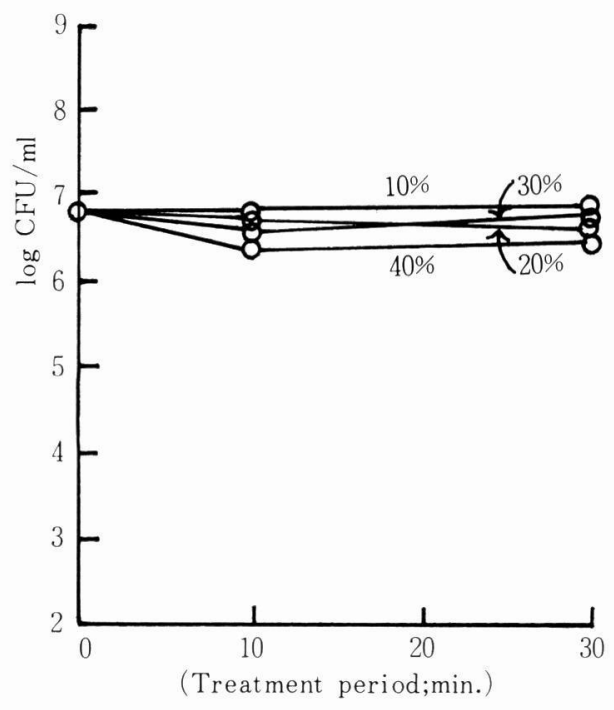

Fig. 4. Inactivation of A. laidlawii $A$ by various concentrations of PEG 6000 . indicate that the lower the molecular weight, the greater is the toxicity of polyethylene glycols.

Results of experiments on the relationship between the concentration of PEGs to be added and the inactivation of $A$. laidlawii A are shown in Figs. 3 and 4. As shown in Fig. 3, an increase in the concentration of PEG 200 resulted in a decrease in surviving cells of A. laidlawii A. In contrast, no such relationship was found when PEG 6000 was used, i. e., even with treatment with the $40 \%$ solution of PEG 6000 , the inactivation was very weak as compared with that of PEG 200. The other polyethylene glycols caused inactivation intermediate between PEG 200 and 6000 (data not shown). $M$. pulmonis showed the same response to PEGs as A. laidlawii A. These results indicate that not only in $A$. laidlawii $\mathrm{A}$, but also in $M$. pulmonis M 53, the higher the concentration of PEG, the greater is the toxicity of PEGs.

All of the above results were obtained by using mycoplasmal cells suspended in phosphate buffered saline. When mycoplasmal cells in culture medium containing horse serum were used for the experiment, the effect of PEG was significantly reduced; for example, no inactivation of mycoplasmas was found even after treatment with PEG 200 (data not shown).

\section{Discussion}

This report presents evidence indicating that the lower the molecular weight and the higher the concentration of polyethylene glycols, the greater is the toxicity to M. pulmonis M53 and A. laidlawii A. In other words, these toxic effects on survival of mycoplasmal cells were parallel with the increase in concentration of PEG to be added in the cases of the low molecular weight PEGs, i.e., PEG 200 and 600. In contrast, in the higher molecular weight group the toxic effect caused by the high 
concentration PEG solution was markedly reduced as shown in Fig. 4. Therefore, it could be concluded that the low molecular weight PEGs could not be used for experi ments on cell fusion of mycoplasmal cells because of their high toxicity. Our results indicating the high toxicity of the low molecular weight polyethylene glycols conflict with those reported by Prakash and Gabridge, who claimed that low molecular weight polyethylene glycol (M. W. 200) was only slightly toxic to $M$. pneumoniae. This difference seems to come from their experimental procedures, in which they immersed the coverslips with grown $M$. pneumoniae cells into the polyethylene glycol solution and rinsed them several times with saline to eliminate the effect of the polyethylene glycol. It seems that this procedure might wash off cells of $M$. pneumoniae from the coverslips by the aggregating force of the polyethylene glycols and the mechanical force during rinsing. The method used here did not contain such a risk of detaching $M$. pneumoniae cells from the coverslips, because the PEG solution was added directly to the suspension of mycoplasmal cells. However, the differences in the species used by us and by Prakash and Gabri dge should be given careful consideration. It is not yet known which molecular weight polyethylene glycol is adequate for cell fusion in mycoplasmas, since there is no report on successful fusion of mycoplasmas. Therefore, there is no model experimental system to answer this question. However, our results strongly suggest that the poly- ethylene glycols having molecular weights of less than 1000 could not be used for fusion experiments with mycoplasmal cells, because of their high toxicity.

Besides the problem concerning the toxicity of PEG, the inactivation of mycoplasmal cells by PEG was blocked when the PEG was added to culture medium containing horse serum (data not shown). From this finding it might be postulated that either the toxic effect of PEG is neutralized, or the mycoplasmal cells are protected from the toxicity of PEG, by some substance, presumably horse serum. Accordingly, it could be presumed that an experimental system using culture medium cannot be employed for fusion experiments on mycoplasmas if PEG is used. In addition, it is necessary to establish good markers, such as drug resistance, and biological characteristics, for example haemadsorption, for studies on cell fusion of mycoplasmas, because sufficient distinct markers of mycoplasmas have not been discovered so far.

\section{References}

Amikan, D., Razin, S. and Glaser, G. (1982). Ribosomal RNA genes in mycoplasma. Nucl. Acid. Res. 10, 4215-4222.

Prakash, G. and Gabridge, M.G. (1981). Iufluence of the fusogenic agent polyethylene gly col on attachment of Mycoplasma pneumoniae to other cells. Infect. Immun. 32, 969-972.

Sмiтh, P.F. (1956). Quantitative measurement of the growth of pleuropneumonia-like organisms. Appl. Microbiol. 4, 254. 